13;09

\title{
Получение светопоглощающих покрытий искусственных спутников Земли из пористых тантала и вольфрама
}

\author{
(C) Ю.Ж. Тулеушев ${ }^{1,2}$, В.Н. Володин ${ }^{1,3}$, Е.А. Жаканбаев ${ }^{1}$, E.E. Суслов ${ }^{1}$, A.S. Kerimshe ${ }^{1}$ \\ ${ }^{1}$ Институт ядерной фиизики, Алматы, Казахстан \\ ${ }^{2}$ Национальный центр космических исследований и технологий, Алматы, Казахстан \\ ${ }^{3}$ Институт металлургии и обогащения, Алматы, Казахстан \\ E-mail: yuriy.tuleushev@mail.ru
}

Поступило в Редакцию 1 апреля 2019г.

В окончательной редакции 26 декабря 2019 г.

Принято к публикации 26 декабря 2019г.

Путем ионно-плазменного распыления и соосаждения ультрадисперсных частиц Та и $\mathrm{Cd}$, а также $\mathrm{W}$ и $\mathrm{Cd}$, легированных $\mathrm{Nb}$ и Мо, впервые получены покрытия, представленные смесью окристаллизованного кадмия и аморфизованных тугоплавких металлов. В результате вакуумного отжига при $800^{\circ} \mathrm{C}$ в течение $1 \mathrm{~h}$ кадмий полностью испарялся из покрытий с образованием ячеистых структур, степень черноты которых зависит от легирования $\mathrm{Nb}$ и Мо. Наиболее черными были покрытия из пористого тантала, легированного ниобием, и пористого вольфрама, легированного ниобием и молибденом. Полученные черные покрытия имеют электросопротивление, достаточное для стока накапливающегося при взаимодействии с околоземной плазмой заряда.

Ключевые слова: тантал, вольфрам, кадмий, пористые структуры, коэффициент отражения.

DOI: 10.21883/PJTF.2020.07.49213.17815

Для устойчивого долговременного функционирования искусственных спутников Земли большое значение имеют терморегулирующие покрытия - как отражающие излучение, так и поглощающие его (так называемые „черные“) [1]. В настоящее время [2-4] в качестве светопоглощающих покрытий используются эмали АК-512, изготовленные из газовой сажи и акриловой смолы. Основным недостатком светопоглощающих покрытий космического назначения является быстрая деградация и пигмента, и связующего под действием факторов космического пространства: пигмент становится серым, а связующий полимер разрушается.

Создание недеградирующих черных покрытий, работающих устойчиво в условиях космического пространства, возможно, на наш взгляд, на основе пористых тугоплавких металлов. В работах $[5,6]$ показано, что пористое покрытие из тантала или вольфрама может быть получено при совместном напылении тантала или вольфрама и кадмия с последующим испарением кадмия в вакууме при нагреве до температур более $700^{\circ} \mathrm{C}$. В связи с этим представляет интерес исследование пористых тантала и вольфрама, легированных добавками ниобия и молибдена. Указанные покрытия могут быть получены при совместном ионно-плазменном напылении компонентов чередующимися нанослоями и последующем вакуумном отжиге систем тантал-кадмий и вольфрам-кадмий, легированных ниобием и молибденом. Задача настоящей работы - получение светопоглощающих покрытий, использующих принцип работы абсолютно черного тела. Для этого из напыленных многокомпонентных покрытий системы тантал-кадмий и вольфрам-кадмий, легирован- ных ниобием и молибденом, с помощью вакуумного отжига удалялся содержащийся в них кадмий, в результате чего получались пористые металлические покрытия.

Материал для исследования - покрытия систем тантал-кадмий и вольфрам-кадмий, легированные ниобием и молибденом и сформированные в результате соосаждения ультрадисперсных частиц металлов, полученных ионно-плазменным распылением, на холодные подложки из полированной нержавеющей стали.

В экспериментах были использованы тантал (чистотой 99.96 mass \%), вольфрам (99.95\%), ниобий $(99.9 \%)$, молибден $(99.9 \%)$ и кадмий $(99.99 \%)$ в виде мишеней диаметром $40 \mathrm{~mm}$ и толщиной $4 \mathrm{~mm}$. При магнетронном распылении в качестве плазмообразующего газа использовался аргон, подвергшийся очистке на геттере распыленном титане.

Методика формирования образцов многокомпонентных покрытий из сплавов заключалась в ионно-плазменном распылении тантала, вольфрама, ниобия, молибдена и кадмия и их совместном осаждении в виде субслоев толщиной порядка $1 \mathrm{~nm}$ до суммарной толщины пленки $1.5-2 \mu \mathrm{m}$ на перемещающиеся относительно потоков плазмы подложки. Напыление осуществлялось одновременно с трех магнетронов, расположенных на боковых стенках камеры, пространство между которыми разделено устройством для перемещения подложек. Скорость перемещения $5 \cdot 10^{-2} \mathrm{~m} \cdot \mathrm{s}^{-1}$.

Составом покрытия управляли путем изменения соотношения мощностей, подаваемых на магнетроны, распыляющие тантал, вольфрам, ниобий, молибден и кадмий. 
$a$

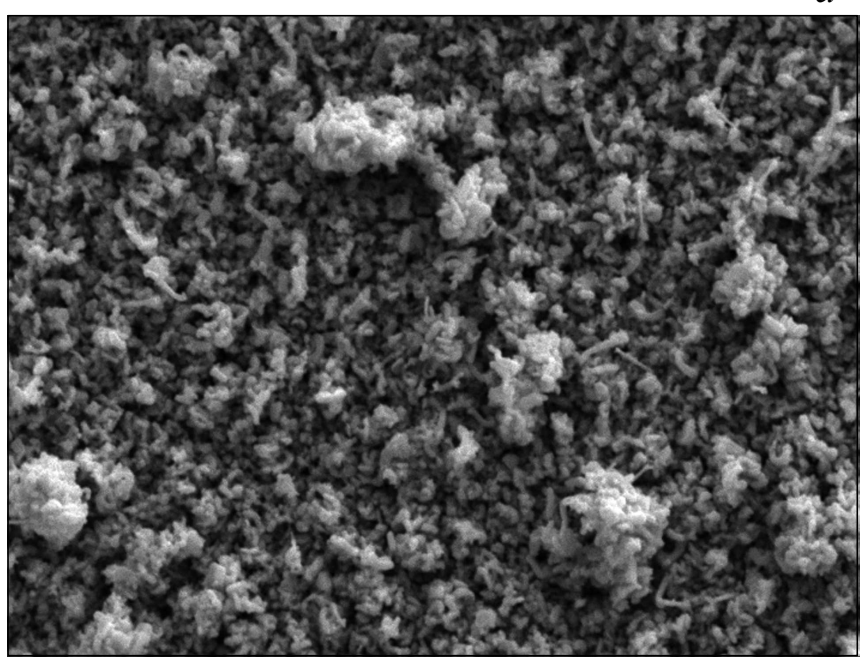

$-1 \mu \mathrm{m}$

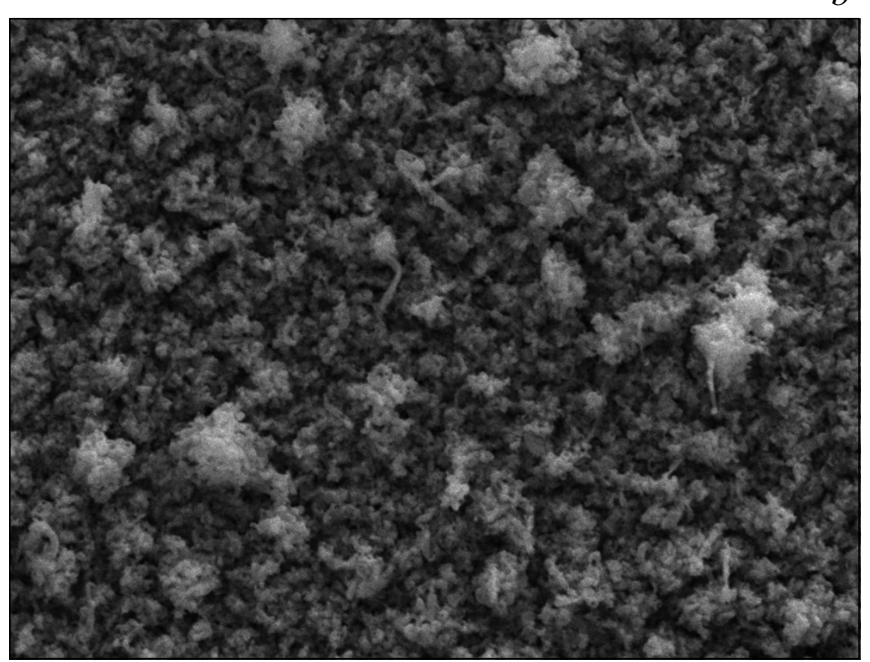

$-1 \mu \mathrm{m}$

Рис. 1. Морфология покрытия $\mathrm{W}-\mathrm{Cd}$, легированного ниобием, до отжига $(a)$ и после отжига $(b)$.

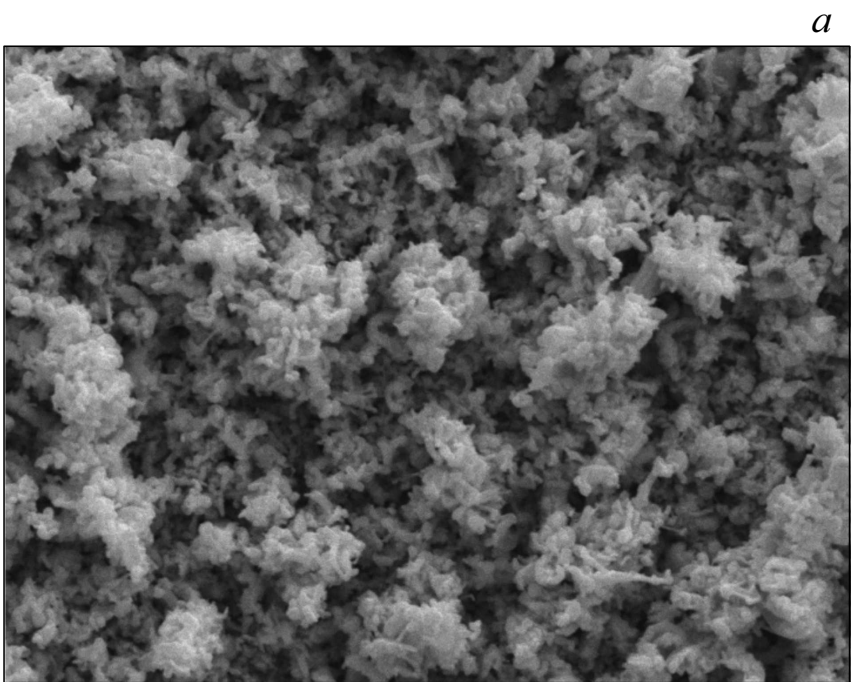

$-1 \mu \mathrm{m}$

$a$

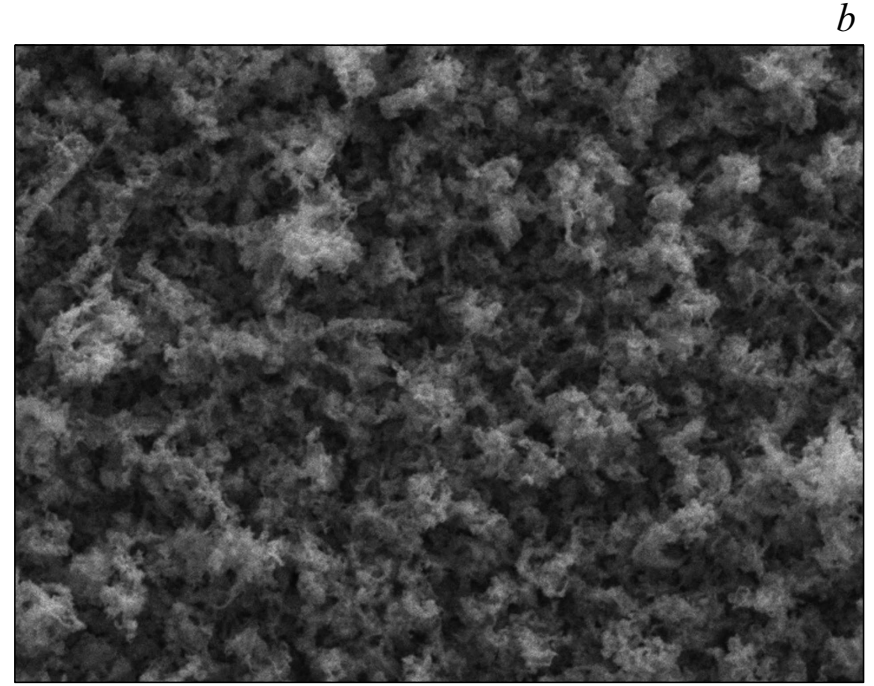

$-1 \mu \mathrm{m}$

Рис. 2. Морфология покрытия $\mathrm{W}-\mathrm{Cd}$, легированного молибденом, до отжига $(a)$ и после отжига $(b)$.

Соотношение осажденных элементов в пленочном покрытии контролировалось с помощью весового метода по количеству распыленного и осажденного Тa, W, $\mathrm{Nb}$, Мо и $\mathrm{Cd}$ во время формирования покрытия. Толщина пленки определялась методом резерфордовского обратного рассеяния протонов на тандемном ускорителе УКП-2-1 и расчетным путем на основании количества осажденных компонентов и их плотности.

Электронно-микроскопические исследования выполнялись на электронно-зондовом микроанализаторе JSM-8230 (JEOL). Спектрофотометрия покрытий из пористых тантала и вольфрама, легированных добавками ниобия и молибдена, на подложках из нержавеющей стали выполнена на установке UV3600 (Shimadzu, Япония).

На рис. 1 и 2 приведены электронно-микроскопические снимки покрытий системы вольфрам-кадмий, легированных ниобием (рис. 1) и молибденом (рис. 2). Из анализа снимков поверхности интерметаллидных покрытий $\mathrm{W}-\mathrm{Cd}$, легированных добавками ниобия и молибдена, следует, что в исходном состоянии покрытие из интерметаллида $\mathrm{W}-\mathrm{Cd}$, легированного ниобием, имеет более мелкодисперсную структуру кристаллитов, чем покрытие из интерметаллида $\mathrm{W}-\mathrm{Cd}$, легированного молибденом. Кристаллиты на рис. 1, $a$ меньше по размеру и упакованы более плотно, чем кристаллиты на рис. 2, $a$. 


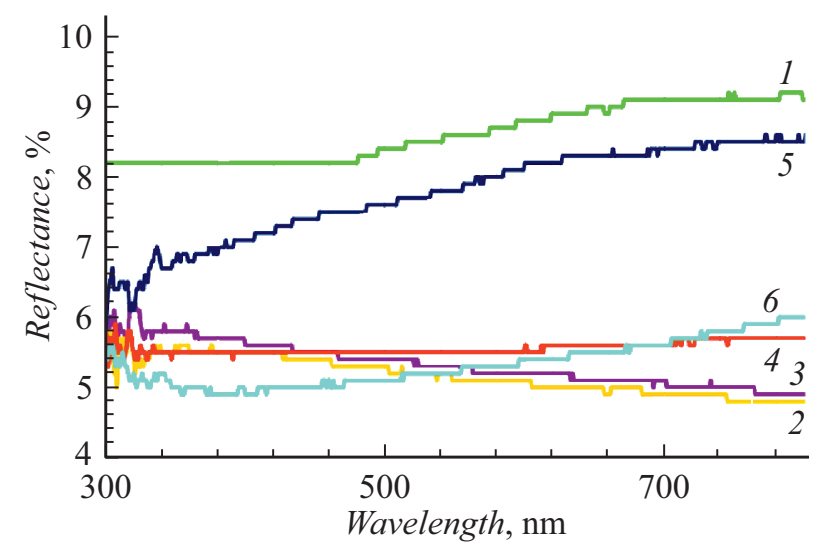

$1-\mathrm{W}-\mathrm{Cd}-3$ on $\mathrm{Si} \quad 4-\mathrm{Ta}-\mathrm{Cd}-\mathrm{Mo}$ on polycore

$2-\mathrm{W}-\mathrm{Cd}-\mathrm{Mo}$ on polycore $5-\mathrm{Ta}-\mathrm{Cd}-2-30$ on $\mathrm{Cu}$ thin foil

$3-\mathrm{W}-\mathrm{Cd}-\mathrm{Nb}$ on polycore $6-\mathrm{Ta}-\mathrm{Cd}-\mathrm{Nb}$ on polycore

Рис. 3. Коэффициенты отражения покрытий из пористых тантала и вольфрама.

После отжига в высоковакуумной печи кадмий из образцов интерметаллида $\mathrm{W}-\mathrm{Cd}$, легированного ниобием, и интерметаллида $\mathrm{W}-\mathrm{Cd}$, легированного молибденом, удален испарением. По данным энергодисперсионной спектроскопии в покрытии вольфрам-кадмий, легированном ниобием, до отжига (рис. 1) было 61.58 at.\% $\mathrm{Cd}$, а после отжига осталось 0.60 at.\% Cd. Примерно та же ситуация с покрытием вольфрам-кадмий, легированным модибденом (рис. 2): 75.14 at.\% Cd до отжига и 0.54 at.\% Cd после отжига. После отжига получены образцы покрытий с бархатисто-черной поверхностью, степень черноты которых определена на спектрофотометре UV-3600.

Измеренные коэффициенты отражения покрытий (рис. 3) из пористых тантала и вольфрама показали, что наиболее черными являются покрытия из пористого тантала, легированного ниобием, и пористого вольфрама, легированного ниобием и молибденом. Коэффициент отражения составил 5\% практически без изменения во всем спектральном диапазоне. Покрытия из пористого тантала на фольге и пористого вольфрама на подложке из кремния, полученные подобным образом, имели коэффициенты отражения, равные соответственно 7 и 8\%. Из этого следует, что наиболее черным является покрытие из пористого тантала, легированного ниобием.

Электрические свойства полученных терморегулирующих покрытий (электросопротивление) измерялись на приборе DT830B, далее рассчитывалось поверхностное электрическое сопротивление, также называемое удельным сопротивлением на квадрат $(\Omega / \mathrm{sq})$. Этот параметр удобен тем, что если покрытия имеют прямоугольную форму, то он не зависит от линейных размеров образца, а определяется только отношением длины к ширине $L / W$. Как известно, для отвода статического электричества с поверхности космического
Поверхностное сопротивление полученных покрытий

\begin{tabular}{c|c|c}
\hline $\begin{array}{r}\text { Номер } \\
\text { образца }\end{array}$ & Система & $\begin{array}{c}\text { Поверхностное сопротивление, } \\
\mathrm{k} \Omega / \mathrm{sq}\end{array}$ \\
\hline 1 & $(\mathrm{~W}-\mathrm{Cd})+\mathrm{Nb}$ & $9.74 \cdot 10^{4}$ \\
2 & $(\mathrm{~W}-\mathrm{Cd})+\mathrm{Mo}$ & $4.17 \cdot 10^{4}$ \\
3 & $(\mathrm{Ta}-\mathrm{Cd})+\mathrm{Nb}$ & $3.99 \cdot 10^{2}$ \\
4 & $(\mathrm{Ta}-\mathrm{Cd})+\mathrm{Mo}$ & $0.12 \cdot 10^{3}$
\end{tabular}

аппарата покрытие должно обладать антистатическими свойствами и иметь поверхностное сопротивление не более $10^{5} \mathrm{k} \Omega / \mathrm{sq}$ [3]. Удельное сопротивление на квадрат рассчитывалось по следующей формуле: $R_{s}=R W / L$, где $R$ - измеренное сопротивление.

Для повышения точности измерения сопротивления покрытия напылялись на изолирующую подложку (поликор). Результаты измерения приведены в таблице.

Как видно из таблицы, все покрытия имеют необходимое и достаточное для снятия остаточного статического электричества поверхностное сопротивление. Исходные (после формирования) покрытия до термообработки обладают более высокой проводимостью, чем покрытия после обработки, что может быть объяснено наличием в исходных образцах аморфной атомной структуры с меньшим количеством границ и пор.

Таким образом, впервые с использованием магнетронной технологии получены „черные“ терморегулирующие покрытия на основе пористых тантала и вольфрама, легированных ниобием и молибденом. Проведенные спектрофотометрические исследования подтверждают, что покрытие из пористого тантала, легированного ниобием, имеет коэффициент отражения менее 5\%. Измерение электропроводности образцов из пористых тантала и вольфрама показало, что изделия, полученные подобным образом, могут быть использованы в качестве терморегулирующих покрытий искусственных спутников Земли.

\section{Финансирование работы}

Работа выполнена при финансовой поддержке Комитета науки Министерства образования и науки Республики Казахстан (гранты № АР05130933/ГФ5 и АР05130967/ГФ5).

\section{Конфликт интересов}

Авторы заявляют, что у них нет конфликта интересов.

\section{Список литературы}

[1] Королев С.И. Системы обеспечения теплового режима космических аппаратов. СПб.: Балт. гос. техн. ун-т, 2006. $100 \mathrm{c}$.

[2] Михайлов М.M. Прогнозирование оптической деградации терморегулирующих покрытий космических аппаратов. Новосибирск: Наука, 1999. 192 с. 
[3] Акишин А.И. Космическое материаловедение. М: НИИЯФ МГУ, 2007. $209 \mathrm{c}$.

[4] Яковлев А.Д. Химия и технология лакокрасочных покрытий. СПб.: Химиздат, 2010. 446 с.

[5] Тулеушев Ю.Ж., Володин В.Н., Бродский А.Р. // ЖТФ. 2015. T. 85. B. 8. C. $53-57$.

[6] Тулеушев Ю.Ж., Володин В.Н., Жаканбаев Е.А., Сукуров Б.М., Козловский А.Л. // Письма в ЖТФ. 2018. Т. 44. B. 11. C. $63-70$. 